\title{
Risk factors associated with nasopharyngeal carriage and density of Streptococcus pneumoniae, Haemophilus influenzae, Moraxella catarrhalis, and Staphylococcus aureus in young children living in Indonesia
}

Eddy Fadlyana', Eileen M. Dunne ${ }^{2,3}$, Kusnandi Rusmil $^{1}$, Rodman Tarigan' ${ }^{1}$, Sunaryati Sudigdoadi ${ }^{4}$, Chrysanti Murad $^{4}$, Emma Watts ${ }^{2}$, Cattram Nguyen ${ }^{2,3}$, Catherine Satzke ${ }^{2,3,5}$, Nurhandini Eka Dewi ${ }^{6}$, Sang Ayu Kompiyang Indriyani ${ }^{7}$, Finny Fitry Yani $^{8}$, Kim Mulholland ${ }^{2,9}$ and Cissy Kartasasmita ${ }^{1 *}$

\begin{abstract}
Background: Potentially pathogenic bacteria Streptococcus pneumoniae, Haemophilus influenzae, Moraxella catarrhalis, and Staphylococcus aureus are commonly carried in the nasopharynx of young children. Host and environmental factors have been linked with pathogen carriage, and in many studies rural children have higher carriage rates than their urban counterparts. There are few published data on what factors contribute to increased pathogen density. The objectives of this study were to identify risk factors for nasopharyngeal carriage and density of $S$. pneumoniae, H. influenzae, M. catarrhalis, and S. aureus in young children in Indonesia.

Methods: Risk factor analysis was done using data on bacterial carriage and participant characteristics from a cross-sectional study that enrolled 302 children aged 12-24 months living in urban or semi-rural areas of Indonesia. Associations between host factors and odds of pathogen carriage were explored using logistic regression. Characteristics identified to be independent predictors of carriage by univariable analysis, as well as those that differed between urban and semi-rural participants, were included in multivariable models. Risk factors for increased pathogen density were identified using linear regression analysis.
\end{abstract}

Results: No differences in carriage prevalence between urban and semi-rural children were observed. Multiple children under the age of 5 years in the household $(<5 \mathrm{y})$ and upper respiratory tract infection (URTI) symptoms were associated with S. pneumoniae carriage, with adjusted odds ratios (aOR) of $2.17(95 \% \mathrm{Cl} 1.13,4.12)$ and 2.28 (95\% Cl 1.15, 4.50), respectively. There was some evidence that URTI symptoms (aOR 1.94 [95\% Cl 1.00, 3.75]) were associated with carriage of $M$. catarrhalis. Children with URTI symptoms $(p=0.002)$, and low parental income $(p=0.011)$ had higher S. pneumoniae density, whereas older age was associated with lower S. pneumoniae density $(p=0.009)$. URTI symptoms were also associated with higher M. catarrahlis density $(p=0.035)$. Low maternal education $(p=0.039)$ and multiple children $<5 y(p=0.021)$ were positively associated with $H$. influenzae density, and semi-rural residence was associated with higher $S$. aureus density $(p<0.001)$.

(Continued on next page)

\footnotetext{
* Correspondence: cbkarta@gmail.com

${ }^{1}$ Department of Child Health, Universitas Padjadjaran/Hasan Sadikin General

Hospital, Bandung, West Java, Indonesia

Full list of author information is available at the end of the article
}

(c) The Author(s). 2018 Open Access This article is distributed under the terms of the Creative Commons Attribution 4.0 International License (http://creativecommons.org/licenses/by/4.0/), which permits unrestricted use, distribution, and reproduction in any medium, provided you give appropriate credit to the original author(s) and the source, provide a link to the Creative Commons license, and indicate if changes were made. The Creative Commons Public Domain Dedication waiver (http://creativecommons.org/publicdomain/zero/1.0/) applies to the data made available in this article, unless otherwise stated. 
(Continued from previous page)

Conclusions: This study provides a detailed assessment of risk factors associated with carriage of clinically-relevant bacteria in Indonesian children, and new data on host factors associated with pathogen density.

Keywords: Nasopharynx, Risk factors, Stunting, Carriage, Density, Streptococcus pneumoniae, Pneumococcus, Haemophilus influenzae, Moraxella catarrhalis, and Staphylococcus aureus

\section{Background}

The nasopharynx of young children is commonly colonized by potentially pathogenic bacteria including Streptococcus pneumoniae (the pneumococcus), Haemophilus influenzae, Moraxella catarrhalis, and Staphylococcus aureus. S. pneumoniae, $H$. influenzae, and $S$. aureus are major causes of pneumonia, the second most common killer (behind preterm birth complications) of children under the age of five years worldwide [1, 2]. S. pneumoniae, $H$. influenzae, and $M$. catarrhalis are the leading etiologic agents associated with otitis media [3]. Carriage of these species is generally asymptomatic, but particularly for S. pneumoniae, carriage is considered a prerequisite for disease as well as the source of transmission [4]. S. pneumoniae carriage prevalence varies from 19 to $86 \%$ depending on factors such as age, geographic location, and HIV status [4]. A meta-analysis reported a pooled prevalence estimate of $47.8 \%$ for pneumococcal carriage in children under five in lowermiddle income countries and $64.8 \%$ in low income countries [5]. PCR detection of $H$. influenzae carriage in healthy children from low and lower-middle income countries ranges from 31 to $70 \%$ [5]. Reported carriage rates of $M$. catarrhalis in children under two years of age range from 25 to $76 \%[6,7]$. S. aureus carriage is highest in early infancy and older children, and typically low (prevalence $<10 \%$ ) in children aged 12-24 months [6-8].

Several host and environmental factors have been associated with increased risk of S. pneumoniae carriage in children, including day care attendance, having siblings or living with other young children, symptoms of respiratory infection, and low socio-economic status [9-13]. Additionally, children in rural areas have been found to have higher S. pneumoniae carriage rates than children in urban settings $[14,15]$. Symptoms of respiratory infection and day-care attendance have been identified as risk factors for $H$. influenzae carriage in children, and low socio-economic status and parents who smoke for M. catarrhalis $[11,13,16]$. In contrast, risk factors typically associated with $S$. pneumoniae carriage, such as day-care attendance, having younger siblings, or living in a rural area, are associated with reduced risk of $S$. aureus carriage $[5,9]$. In studies including HIV-positive children, HIV infection was a risk factor for $S$. aureus carriage, whereas associations between HIV status and S. pneumoniae carriage have varied [17-19]. In HIV-infected children, respiratory infection has been identified as a risk factor for S. pneumoniae carriage, coryza and school attendance were linked to higher S. aureus carriage, and M. catarrhalis carriage was more common in children from urban settings compared to rural, as well as those whose mothers had higher levels of education [20,21].

In addition to the presence of a potential pathogen in the nasopharynx, the quantitative bacterial load (density) has been increasingly recognized as clinically important. High S. pneumoniae density in the nasopharynx has been associated with respiratory infection and pneumonia in children, and linked to transmission in animal studies [22, 23]. Nasopharyngeal density of S. pneumoniae, $H$. influenzae, and $M$. catarrhalis was found to be higher in children with otitis media compared to healthy controls [24]. There are few published data on risk factors associated with increased bacterial density in the nasopharynx, however co-infection with respiratory viruses is associated with increased density of S. pneumoniae and H. influenzae [24, 25].

Indonesia is a lower-middle income country with an estimated population of over 260 million, the world's fourth highest (www.worldbank.org). Pneumonia is the most common cause of death in the post-neonatal period in Indonesian children, and in 2013 was estimated to kill 22,000 children [26]. Indonesia is a diverse country composed of over 17,000 islands. Childhood mortality varies significantly among island regions and between urban and rural areas [27]. Vaccines against $H$. influenzae type B (Hib) were introduced in Indonesia in 2013. Pneumococcal conjugate vaccines are not yet part of the national immunization program, although a government-led demonstration program of PCV13 commenced in late 2017 in West Nusa Tenggara. Previously, we conducted a cross-sectional carriage study in children 12-24 months of age in three Indonesian regions and reported a carriage prevalence of $49.5 \%$ for S. pneumoniae, $27.5 \%$ for $\mathrm{H}$. influenzae, $42.7 \%$ for $M$. catarrhalis, and $7.3 \%$ for S. aureus [28]. No Hib carriage was detected due to vaccine use. The S. pneumoniae carriage rate was similar to previous reports from Central Java and Lombok, which ranged from 43 to $48 \%$ [29-31]. In Semarang, Central Java, S. pneumoniae carriage rates varied by district, with higher rates found in suburban areas [29]. Here, we examine risk factors for pathogen carriage and density in children from semi-rural and urban areas using data from this cross-sectional study. We hypothesized that children from semi-rural areas would have higher odds of pathogen carriage. 


\section{Methods}

\section{Study design and participants}

Details on the study participants and laboratory methods were previously published [28]. In brief, 302 healthy children aged 12-24 months were enrolled at six health centers located in three different regions of Indonesia: Bandung, West Java; Lombok, West Nusa Tenggara, and Padang, West Sumatra. Half of the children were from urban communities and the other half from semi-rural areas. Recruitment was conducted by health center staff, who invited age-eligible children and their parents to participate. Inclusion criteria were age 12-24 months and residence within the health center jurisdiction. Exclusion criteria were moderate or severe acute illness, temperature $\geq 38^{\circ} \mathrm{C}$, antibiotic use within the previous 14 days, or previous receipt of pneumococcal conjugate vaccine.

For each participant, a medical examination was conducted by a pediatrician, and data on demographic characteristics, living conditions, and significant medical history were recorded on a case report form. Anthropometric measurements ( $\mathrm{Z}$ scores) were calculated in Stata version 14.2 (StataCorp, College Station, TX, USA) using the Stata macro available online from the World Health Organization (WHO; http://www.who.int/childgrowth/ software/en/, accessed 7 March 2018), with stunting defined as length-for-age $\mathrm{z}$-score below -2 standard deviations of the median length-for-age of the WHO Child Growth Standards [32]. A nasopharyngeal swab was collected according to WHO recommendations and placed immediately into $1 \mathrm{~mL}$ skim milk tryptone glucose glycerol media (STGG) media [33]. Swabs were kept in a cool box and transported to a local laboratory within $6 \mathrm{~h}$ of collection for aliquotting and storage at $-70{ }^{\circ} \mathrm{C}$ until use. Swabs from Lombok and Padang regions were shipped to the central laboratory in Bandung on dry ice, then stored at $-70{ }^{\circ} \mathrm{C}$.

\section{Laboratory analyses}

DNA was extracted from $200 \mu$ l of STGG sample using a QIAcube HT instrument (Qiagen) following enzymatic lysis. Bacteria were pelleted by centrifugation at $5500 \mathrm{x} \mathrm{g}$ for $8 \mathrm{~min}$ and lysis was conducted by incubation in a 20 $\mathrm{mM}$ Tris- $\mathrm{HCl}, 2 \mathrm{mM}$ sodium EDTA buffer containing 20 $\mathrm{mg} / \mathrm{ml}$ lysozyme, $1 \%(\mathrm{v} / \mathrm{v})$ Triton X-100, $0.075 \mathrm{mg} / \mathrm{ml}$ mutanolysin and $2 \mathrm{mg} / \mathrm{ml}$ RNase A for $60 \mathrm{~min}$ at $37^{\circ} \mathrm{C}$, followed by the addition of proteinase $\mathrm{K}$ and Buffer AL from the QIAamp 96 DNA QIAcube HT Kit (Qiagen) and $30 \mathrm{~min}$ incubation at $56^{\circ} \mathrm{C}$. Lysates were transferred onto the QIAcube HT instrument (Qiagen) and DNA extraction performed according to the manufacturer's instructions.

S. pneumoniae was detected and quantified using a real-time quantitative PCR (qPCR) assay targeting the lytA gene with confirmation by culture on sheep blood agar containing $5 \mu \mathrm{g} / \mathrm{ml}$ gentamicin [34]. A commercial kit (FTD Bacterial Pneumonia CAP qPCR kit; Fast-Track Diagnostics) was used for detection and quantification of $H$. influenzae, M. catarrhalis, and S. aureus. Full details are available in the Additional file 1.

\section{Statistical analysis}

Data from case report forms was entered into a database (dBASE software, dBase LLC, Binghamton, NY, USA) and laboratory data entered into Microsoft Excel 2013. Datasets were imported, merged, and cleaning conducted using Stata version 14.2 (StataCorp, College Station, TX, USA), and statistical analyses were conducted using Stata version 14.2. To compare data between urban and semirural participants, the chi-squared test was used for categorical data and the t-test for continuous data following assesment of normality. For examination of potential risk factors for carriage, univariable odds ratios and 95\% confidence intervals (CIs) were calculated using logistic regression. The following variables (shown in Table 1) were assessed: region, sex, residence (urban or semi-rural), age, stunting (defined as length-for-age z-score below - 2), maternal education, income, having two or more children under five years old in the household, upper respiratory tract infection (URTI) symptoms (rhinorrhea, cough, and/ or tonsillitis), exposure to cigarette smoke, and presence of a wood-fuelled stove in the home. Two categorical variables were reclassified into binary variables prior to analysis: maternal education (below high school and high school or above) and income (at or below regional minimum salary or above regional minimum salary). Regional minimum salary rates in 2016 were 1,800,725 Indonesian rupiah (IDR) in Padang, 2,626,940 IDR in Bandung, and $1,550,000$ IDR in Lombok. Paternal education was not included in analysis due to co-linearity with maternal education. Carriage of other colonizing pathogens was also included in risk factor evaluation.

Multivariable logistic regression models were created for each pathogen to estimate adjusted odds ratios and 95\% CI. Multivariable models included the following variables: residence (selected a priori), variables that varied between urban and semi-rural participants (income, exposure to cigarette smoke, having a wood-fuelled stove), and any other variables with $p<0.1$ by univariable analysis.

Bacterial density data were $\log _{10}$ transformed prior to analysis and reported as $\log _{10}$ genome equivalents $/ \mathrm{ml}$ $\left(\log _{10} \mathrm{GE} / \mathrm{ml}\right)$. Linear regression was used to examine relationships between potential risk factors and bacterial density, with analyses restricted to positive carriers for each species. The same variables used for risk factors for carriage were queried for association with density. Results were reported as linear regression coefficients and 95\% CI. Covariates for the multivariable linear regression models used to estimate adjusted coefficients included 
Table 1 Characteristics of study participants

\begin{tabular}{|c|c|c|c|c|}
\hline Characteristics & $\begin{array}{l}\text { All participants (total }=302 \text { ) } \\
\text { N }(\%)\end{array}$ & $\begin{array}{l}\text { Urban }(n=152) \\
\mathrm{N}(\%)\end{array}$ & $\begin{array}{l}\text { Semi-rural }(n=150) \\
\mathrm{N}(\%)\end{array}$ & $P$ value \\
\hline \multicolumn{5}{|l|}{ Region } \\
\hline Bandung & $100(33.1)$ & $50(32.9)$ & $50(33.3)$ & \multirow[t]{3}{*}{0.997} \\
\hline Lombok & $101(33.4)$ & $51(33.6)$ & $50(33.3)$ & \\
\hline Padang & $101(33.4)$ & $51(33.6)$ & $50(33.3)$ & \\
\hline \multicolumn{5}{|l|}{ Sex } \\
\hline Male & $158(52.3)$ & $82(53.9)$ & $76(50.7)$ & \multirow[t]{2}{*}{0.568} \\
\hline Female & $144(47.7)$ & $70(46.0)$ & $74(49.3)$ & \\
\hline \multicolumn{5}{|l|}{ Age (months) } \\
\hline Mean \pm SD & $18.9 \pm 3.3$ & \multirow[t]{2}{*}{$18.8 \pm 3.3$} & \multirow[t]{2}{*}{$18.9 \pm 3.3$} & \multirow[t]{2}{*}{0.852} \\
\hline Min; Max & $12.3 ; 24.9$ & & & \\
\hline \multicolumn{5}{|l|}{ Weight (kg) } \\
\hline Mean \pm SD & $9.5 \pm 1.4$ & \multirow[t]{2}{*}{$9.4 \pm 1.3$} & \multirow[t]{2}{*}{$9.5 \pm 1.4$} & \multirow[t]{2}{*}{0.472} \\
\hline Min; Max & $6.4 ; 15.0$ & & & \\
\hline \multicolumn{5}{|l|}{ Length $(\mathrm{cm})$} \\
\hline Mean \pm SD & $78.8 \pm 4.2$ & $79.0 \pm 4.1$ & $78.5 \pm 4.4$ & \multirow[t]{2}{*}{0.287} \\
\hline Min; Max & $67 ; 91$ & & & \\
\hline \multicolumn{5}{|l|}{ Length-for-age Z score } \\
\hline Mean \pm SD & $-1.20 \pm 1.22$ & $-1.11 \pm 1.20$ & $-1.30 \pm 1.22$ & \multirow[t]{2}{*}{0.175} \\
\hline Min; Max & $-4.33 ; 4.19$ & $-3.81 ; 4.19$ & $-4.33 ; 1.65$ & \\
\hline \multicolumn{5}{|l|}{ Stunting ${ }^{2}$} \\
\hline No & $221(73.2)$ & $116(76.3)$ & $105(70.0)$ & \multirow[t]{2}{*}{0.215} \\
\hline Yes & $81(26.8)$ & $36(23.7)$ & $45(30.0)$ & \\
\hline \multicolumn{5}{|l|}{ Paternal education } \\
\hline None & $10(3.3)$ & $5(3.3)$ & $5(3.3)$ & \multirow[t]{5}{*}{0.739} \\
\hline Elementary school & $32(10.6)$ & $15(9.9)$ & $17(11.3)$ & \\
\hline Junior high school & $61(20.2)$ & $28(18.4)$ & $33(22.0)$ & \\
\hline Senior high school & $155(51.3)$ & $78(51.3)$ & 77 (51.3) & \\
\hline University & 44 (14.6) & $26(17.1)$ & $18(12.0)$ & \\
\hline \multicolumn{5}{|l|}{ Maternal education } \\
\hline None & $11(3.6)$ & $7(4.6)$ & $4(2.7)$ & \multirow[t]{5}{*}{0.470} \\
\hline Elementary school & $30(9.9)$ & $13(8.6)$ & $17(11.3)$ & \\
\hline Junior high school & $78(25.8)$ & $34(22.4)$ & $44(29.3)$ & \\
\hline Senior high school & $147(48.7)$ & $79(52.0)$ & $68(45.3)$ & \\
\hline University & $36(11.9)$ & $19(12.5)$ & $17(11.3)$ & \\
\hline \multicolumn{5}{|l|}{ Parental monthly income ${ }^{3}$} \\
\hline Declined to answer & $2(0.7)$ & $0(0.0)$ & $2(1.3)$ & \multirow[t]{4}{*}{0.041} \\
\hline$<500,000$ IDR & $43(14.2)$ & $29(19.1)$ & $43(14.2)$ & \\
\hline 500,000 IDR - Regional minimum salary & $167(55.3)$ & $77(50.7)$ & $90(60.0)$ & \\
\hline$>$ Regional minimum salary & $90(29.8)$ & $46(30.3)$ & $44(29.3)$ & \\
\hline \multicolumn{5}{|l|}{ Number of children $<5 y$ in the household ${ }^{4}$} \\
\hline 1 & $237(78.5)$ & $114(76.5)$ & $123(82.0)$ & 0.378 \\
\hline 2 & $48(15.9)$ & $27(18.1)$ & $21(14.0)$ & \\
\hline 3 & $12(4.0)$ & $6(4.0)$ & $6(4.0)$ & \\
\hline
\end{tabular}


Table 1 Characteristics of study participants (Continued)

\begin{tabular}{|c|c|c|c|c|}
\hline Characteristics & $\begin{array}{l}\text { All participants (total = 302) } \\
\text { N (\%) }\end{array}$ & $\begin{array}{l}\text { Urban }(n=152) \\
\mathrm{N}(\%)\end{array}$ & $\begin{array}{l}\text { Semi-rural }(n=150) \\
\mathrm{N}(\%)\end{array}$ & $P$ value $^{1}$ \\
\hline 4 & $2(0.7)$ & $2(1.3)$ & $0(0.0)$ & \\
\hline \multicolumn{5}{|c|}{ Exposure to indoor cigarette smoke } \\
\hline No & $163(54.0)$ & $98(64.5)$ & $65(43.3)$ & \multirow[t]{2}{*}{0.0004} \\
\hline Yes & $139(46.0)$ & $54(35.5)$ & $85(56.7)$ & \\
\hline \multicolumn{5}{|c|}{ Wood-fuelled stove in home } \\
\hline No & $268(88.7)$ & $146(96.0)$ & $122(81.3)$ & \multirow[t]{2}{*}{0.0001} \\
\hline Yes & $34(11.3)$ & $6(4.0)$ & $28(18.7)$ & \\
\hline \multicolumn{5}{|c|}{ URTI symptoms ${ }^{5}$} \\
\hline No & $240(79.5)$ & $127(83.6)$ & $113(75.3)$ & \multirow[t]{2}{*}{0.077} \\
\hline Yes & $62(20.5)$ & $25(16.4)$ & $37(24.7)$ & \\
\hline
\end{tabular}

${ }^{1}$ Chi-squared test for categorical data; t-test for continuous data

${ }^{2}$ Stunting (chronic undernutrition) defined as length-for-age $Z$ score below -2

${ }^{3}$ IDR Indonesian rupiah; Regional minimum salary rates (2016) were 1,800,725 IDR in Padang, 2,626,940 IDR in Bandung, and 1,550,000 IDR in Lombok

${ }^{4}$ Data missing from three urban participants ( $n=299$ total, $n=149$ urban)

${ }^{5}$ Upper respiratory tract infection (URTI) symptoms include rhinorrhea, cough, and/or tonsillitis

variables with $p<0.1$ by univariable analysis as well as residence type, income, and having a wood-fuelled stove.

\section{Results}

Three hundred and two children aged 12-24 months were included in this study, with 152 participants from urban areas and 150 from semi-rural areas. The characteristics of the study participants are shown in Table 1. Most characteristics were similar between the urban and semi-rural children, except that exposure to indoor cigarette smoke and having a wood-fuelled stove were higher for semi-rural children, and the income distribution differed between the two groups. The carriage prevalence for S. pneumoniae, $H$. influenzae, $M$. catarrhalis, and $S$. aureus for urban and semi-rural participants is shown in Fig. 1. There were no significant differences in carriage prevalence between urban and semi-rural children for $S$. pneumoniae, $H$. influenzae, or $S$. aureus ( $p>0.10$ for each). There was some evidence that carriage prevalence of $M$. catarrhalis was higher in semi-rural children $(p=0.065)$. $101(33.4 \%)$ study participants carried one of the four bacterial species examined, and 125 (41.2\%) carried multiple species. There was no difference in multiple species carriage prevalence between urban and semi-rural children $(p=0.496)$.

The relationships between participant characteristics and carriage of each species were examined using logistic regression analysis. For $S$. pneumoniae, univariable analysis found carriage differed between regions, with children in Bandung and Lombok having higher odds of pneumococcal carriage compared to children in Padang (Table 2). Low maternal education, stunting, the presence of URTI symptoms, and carriage of $M$. catarrhalis were significantly associated with increased odds of pneumococcal carriage. Following multivariable analysis region, living in a household with two or more children under the age of five, URTI symptoms, and $M$. catarrhalis carriage remained significant. For $M$. catarrhalis, carriage varied by region, with higher odds reported for children in Lombok compared to Padang (Table 2). Following multivariable analysis, URTI symptoms, S. pneumoniae carriage, and $H$. influenzae carriage were positively associated with M. catarrhalis carriage, whereas S. aureus carriage was negatively associated. Following adjustment, semi-rural residence was not associated with $M$. catarrhalis carriage $(p=0.205)$. There were no demographic factors that were significantly associated with carriage of $H$. influenzae or $S$. aureus, however carriage of $M$. catarrhalis was positively associated with $H$. influenzae and negatively associated with S. aureus (Additional file 1: Table S1). Potential risk factors for carriage of more than one species were also examined, and URTI symptoms had a strong positive association (aOR 3.2 [95\%CI 1.69, 6.11]) by multivariable analysis (Additional file 1: Table S2).

In children positive for carriage, we sought to identify host and environmental factors associated with increased density using linear regression analysis. For S. pneumoniae, children from families in the higher income category had lower pneumococcal carriage densities, and density decreased with age (Table 3). Children with URTI symptoms or were co-colonized by either $H$. influenzae or $M$. catarrhalis had higher pneumococcal carriage densities (Table 3). For $H$. influenzae, children with two or more children under the age of five in the household had higher carriage density, whereas children whose mothers had higher education levels or who had a wood-fuelled stove in the home had lower carriage density (Table 4). For $M$. catarrhalis carriers, URTI symptoms were associated with higher density (Table 5). For S. aureus, children living in semi-rural areas had 


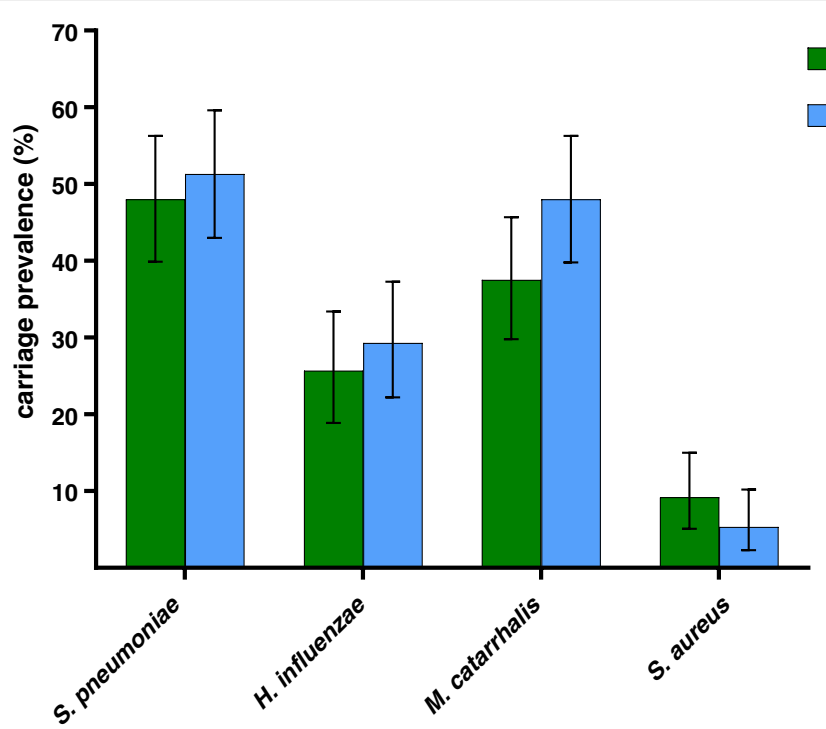

Fig. 1 Nasopharyngeal carriage prevalence of potentially pathogenic bacteria in Indonesian children aged 12-24 months living in urban (green) or semi-rural (blue) areas. Error bars depict 95\% confidence intervals

higher density compared to children from urban areas (Additional file 1: Table S3). When the densities of any of the four bacterial species detected were combined, URTI symptoms were positively associated with total density following multivariable analysis (Additional file 1: Table S4).

\section{Discussion}

Using data from a cross-sectional study, we identified risk factors associated with carriage and/or density of four clinically-relevant bacterial species in Indonesian children. Contrary to expectation, we did not observe major differences in carriage of these bacterial species between children living in urban and semi-rural environments, although semi-rural children had higher densities of $S$. aureus compared to urban children. Of the potential risk factors assessed, the majority did not differ between these two groups. The semi-rural sites involved in our study were located within an hour drive of the urban areas to enable timely storage of samples. It is possible that children in more remote rural areas may have different characteristics and increased risk of bacterial carriage than the children assessed in our study. We also only included sites from three of Indonesia's 34 provinces. HIV status was not determined for participants in our study, but HIV prevalence in Indonesian children is likely quite low, as overall prevalence of $\mathrm{HIV}$ in Indonesia is estimated to be $<0.5 \%$ [35].

The risk factors for S. pneumoniae carriage in our study, the presence of two or more children under the age of five years in the household, and having URTI symptoms, were consistent with studies conducted on children of a similar age in other countries $[10,11]$. Having URTI symptoms was also identified as risk factors for $M$. catarrhalis carriage. We did not identify any epidemiologic factors significantly associated with carriage of $H$. influenzae or $S$. aureus. Interactions between bacterial species may also affect carriage dynamics, and we previously reported positive relationships among S. pneumoniae, $H$. influenzae, and $M$. catarrhalis [28]. Using multivariable models that accounted for bacterial and epidemiologic factors, carriage of $M$. catarrhalis was a risk factor for S. pneumoniae and $H$. influenzae carriage, but negatively associated with $S$. aureus carriage, and vice versa. These relationships are consistent with the literature, and suggest that both intrinsic host factors as well as co-colonizing bacteria influence the nasopharyngeal microbiome $[7,8]$.

Bacterial density in the nasopharynx is linked to both the development of infection and pathogen transmission. In a study in Vietnamese children under five years old, pneumococcal loads in the nasopharynx were significantly higher in children with radiologically confirmed pneumonia compared to children with other lower respiratory tract infection or healthy controls [22]. However, relatively few data on risk factors associated with bacterial density are available. In our study, we identified host, socio-economic, and environmental factors associated with increased bacterial density in the nasopharynx, although results differed depending on the bacterial species. For S. pneumoniae, low parental income, URTI symptoms, and co-colonization with $M$. catarrhalis or $H$. influenzae were associated with increased density, whereas density decreased with age. Declining pneumococcal density with age has been reported previously [36]. URTI symptoms were associated with increased density of S. pneumoniae and M. catarrhalis. It is unclear whether the presence of these 


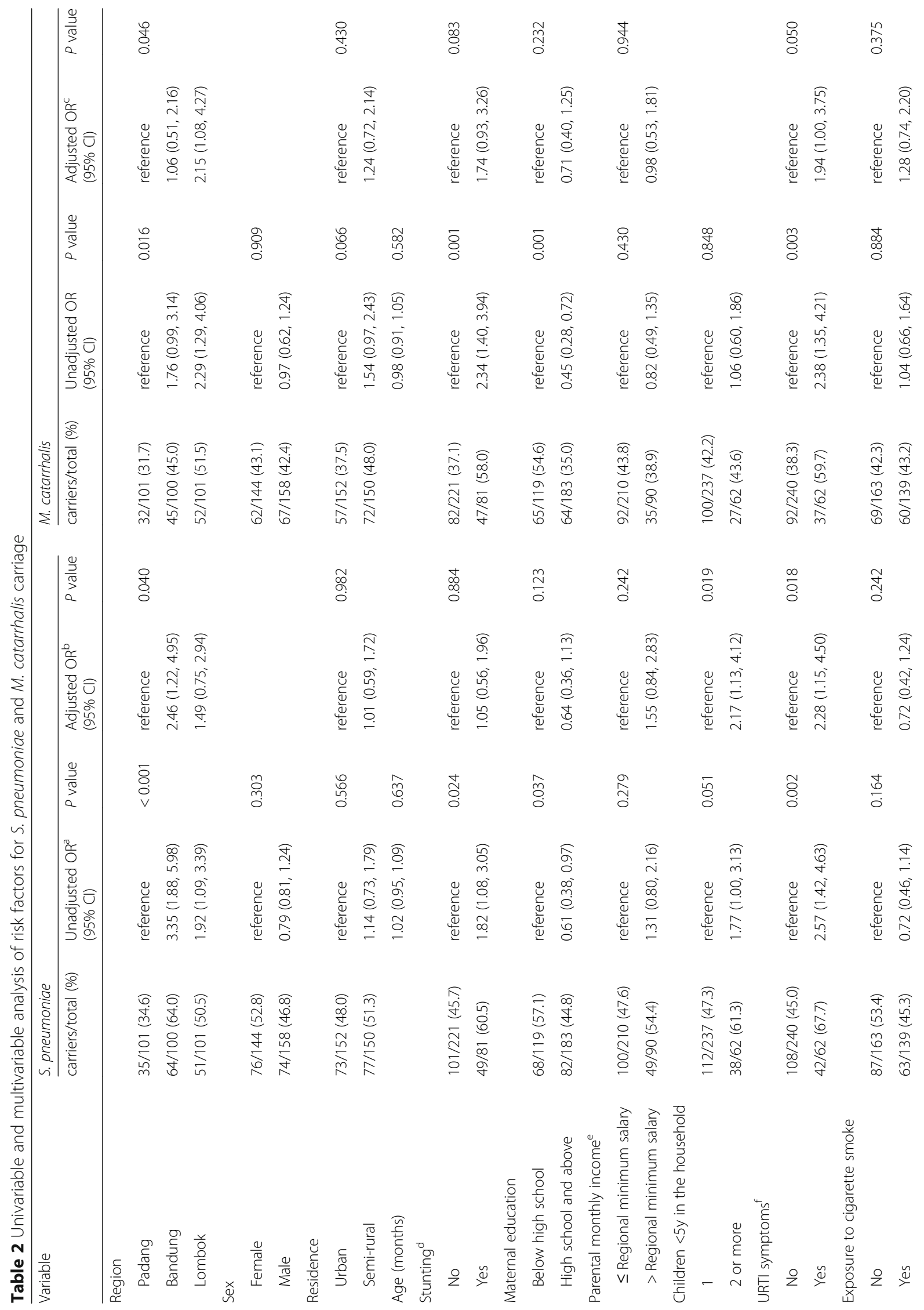




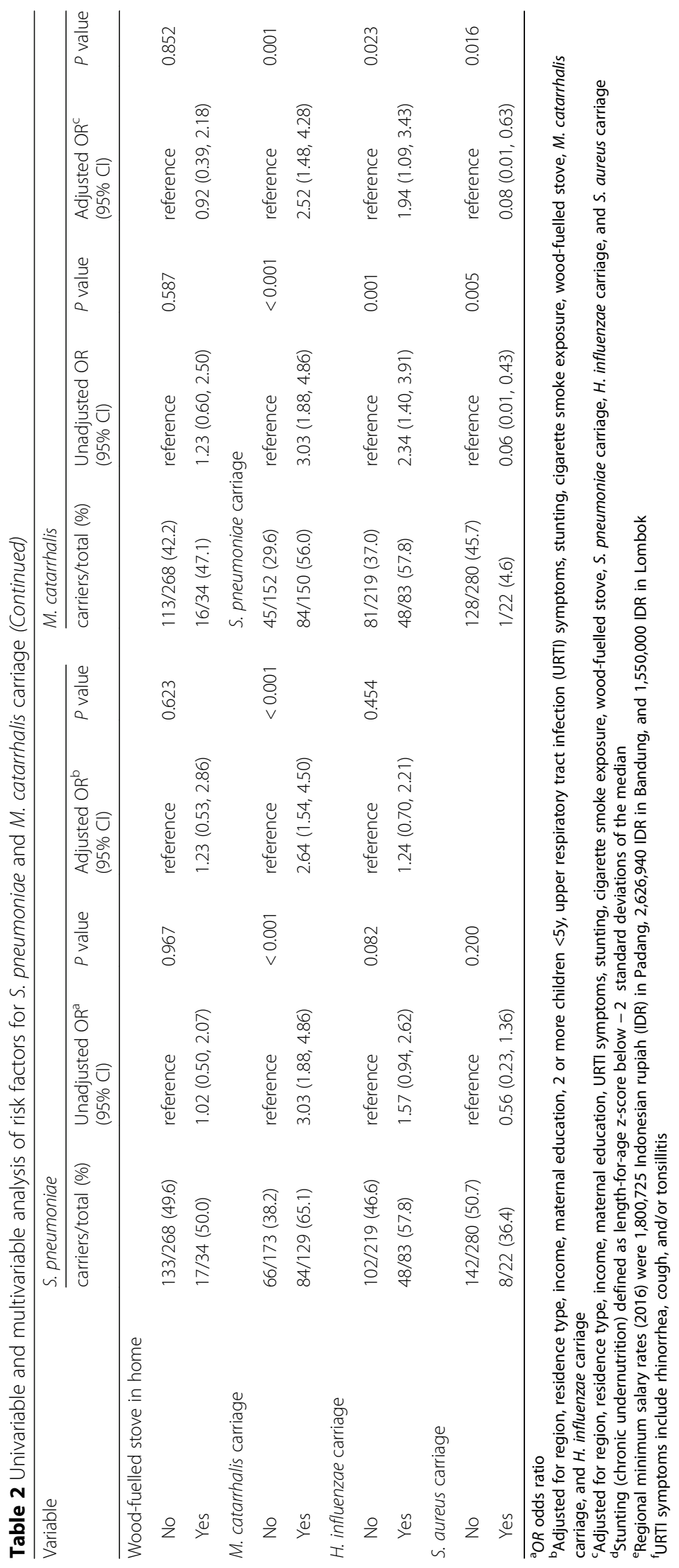


Table 3 Linear regression analysis of factors associated with S. pneumoniae density in children who are carriers $(n=150)$

\begin{tabular}{|c|c|c|c|c|c|}
\hline Variable (n) & Mean density $\left(\log _{10} \mathrm{GE} / \mathrm{ml}\right)^{\mathrm{a}}$ & Unadjusted coefficient $^{\mathrm{b}}(95 \% \mathrm{Cl})$ & $P$ value & Adjusted coefficient ${ }^{c}$ (95\% Cl) & $P$ value \\
\hline \multicolumn{6}{|l|}{ Region } \\
\hline Padang (35) & 5.09 & reference & 0.182 & & \\
\hline Bandung (64) & 5.17 & $0.08(-0.37,0.53)$ & & & \\
\hline Lombok (51) & 4.80 & $-0.29(-0.76,0.18)$ & & & \\
\hline \multicolumn{6}{|l|}{ Sex } \\
\hline Female (76) & 4.92 & reference & 0.224 & & \\
\hline Male (74) & 5.14 & $0.22(-0.31,0.57)$ & & & \\
\hline \multicolumn{6}{|l|}{ Residence } \\
\hline Urban (73) & 5.06 & reference & 0.761 & reference & 0.642 \\
\hline Semi-rural (77) & 5.00 & $-0.05(-0.41,0.30)$ & & $-0.08(-0.41,0.25)$ & \\
\hline Age (months) & 5.03 & $-0.08(-0.13,-0.02)$ & 0.004 & $-0.06(-0.11,-0.02)$ & 0.009 \\
\hline \multicolumn{6}{|l|}{ Stunting $^{d}$} \\
\hline No (101) & 4.89 & reference & 0.025 & reference & 0.142 \\
\hline Yes (49) & 5.31 & $0.42(0.06,0.79)$ & & $0.26(-0.09,0.62)$ & \\
\hline \multicolumn{6}{|l|}{ Maternal education } \\
\hline Below high school (68) & 5.23 & reference & 0.035 & reference & 0.360 \\
\hline High school and above (82) & 4.86 & $-0.38(-0.72,-0.03)$ & & $-0.15(-0.47,0.17)$ & \\
\hline \multicolumn{6}{|l|}{ Parental monthly income $e^{e}$} \\
\hline$\leq$ regional minimum salary (100) & 5.22 & reference & 0.003 & reference & 0.011 \\
\hline > regional minimum salary (49) & 4.67 & $-0.56(-0.92,-0.19)$ & & $-0.47(-0.79,-0.10)$ & \\
\hline \multicolumn{6}{|l|}{ Children $<5 y$ in the household } \\
\hline $1(112)$ & 4.97 & reference & 0.280 & & \\
\hline 2 or more (38) & 5.19 & $0.22(-0.18,0.63)$ & & & \\
\hline \multicolumn{6}{|l|}{ URTI symptoms ${ }^{f}$} \\
\hline No (108) & 4.83 & reference & $<0.001$ & reference & 0.002 \\
\hline Yes (42) & 5.53 & $0.70(0.32,1.08)$ & & $0.55(0.20,0.90)$ & \\
\hline \multicolumn{6}{|l|}{ Exposure to cigarette smoke } \\
\hline No (87) & 4.98 & reference & 0.569 & reference & 0.436 \\
\hline Yes (63) & 5.09 & $0.10(-0.25,0.46)$ & & $0.13(-0.20,0.46)$ & \\
\hline \multicolumn{6}{|l|}{ Wood-fuelled stove in home } \\
\hline No (133) & 5.07 & reference & 0.180 & reference & 0.142 \\
\hline Yes (17) & 4.69 & $-0.38(-0.93,0.18)$ & & $-0.38(-0.89,0.13)$ & \\
\hline \multicolumn{6}{|l|}{ M. catarrhalis carriage } \\
\hline No (66) & 4.70 & reference & 0.001 & reference & 0.038 \\
\hline Yes (84) & 5.28 & $0.58(0.24,0.92)$ & & $0.33(0.02,0.65)$ & \\
\hline \multicolumn{6}{|l|}{ H. influenzae carriage } \\
\hline No (102) & 4.80 & reference & $<0.001$ & reference & 0.005 \\
\hline Yes (48) & 5.52 & $0.73(0.37,1.09)$ & & $0.49(0.15,0.82)$ & \\
\hline \multicolumn{6}{|l|}{ S. aureus carriage } \\
\hline No (142) & 5.08 & reference & 0.019 & reference & 0.536 \\
\hline Yes (8) & 4.15 & $-0.92(-1.70,-0.15)$ & & $-0.22(-0.92,0.48)$ & \\
\hline
\end{tabular}

${ }^{\mathrm{a} S}$. pneumoniae density reported in $\log _{10}$ genome equivalents $/ \mathrm{ml}$

${ }^{\mathrm{b}}$ Coefficient is the difference in means determined by linear regression

'Adjusted for residence type, age, maternal education, income, upper respiratory tract infection (URTI) symptoms, stunting, cigarette smoke exposure,

wood-fuelled stove, $M$. catarrhalis carriage, $H$. influenzae carriage, and $S$. aureus carriage

${ }^{\mathrm{d}}$ Stunting (chronic undernutrition) defined as length/height-for-age $z$-score below -2 standard deviations of the median

${ }^{e}$ Regional minimum salary rates (2016) were 1,800,725 Indonesian rupiah (IDR) in Padang, 2,626,940 IDR in Bandung, and 1,550,000 IDR in Lombok

fURTI symptoms include rhinorrhea, cough, and/or tonsillitis 
Table 4 Linear regression analysis of factors associated with $H$. influenzae density in children who are carriers $(n=83)$

\begin{tabular}{|c|c|c|c|c|c|}
\hline Variable $(\mathrm{n})$ & Mean density $\left(\log _{10} \mathrm{GE} / \mathrm{ml}\right)^{a}$ & Unadjusted coefficient ${ }^{\mathrm{b}}(95 \% \mathrm{Cl})$ & $P$ value & Adjusted coefficient ${ }^{\mathrm{C}}(95 \% \mathrm{Cl})$ & $P$ value \\
\hline \multicolumn{6}{|l|}{ Region } \\
\hline Padang (25) & 5.51 & reference & 0.567 & & \\
\hline Bandung (32) & 5.67 & $0.16(-0.34,0.65)$ & & & \\
\hline Lombok (26) & 5.41 & $-0.10(-0.62,0.42)$ & & & \\
\hline \multicolumn{6}{|l|}{ Sex } \\
\hline Female (42) & 5.41 & reference & 0.188 & & \\
\hline Male (41) & 5.68 & $0.27(-0.13,0.67)$ & & & \\
\hline \multicolumn{6}{|l|}{ Residence } \\
\hline Urban (39) & 5.70 & reference & 0.152 & reference & 0.433 \\
\hline Semi-rural (44) & 5.40 & $-0.29(-0.70,0.11)$ & & $-0.16(-0.55,0.24)$ & \\
\hline Age (in months) & 5.54 & $0.01(-0.05,0.08)$ & 0.653 & & \\
\hline \multicolumn{6}{|l|}{ Stunting $^{d}$} \\
\hline No (55) & 5.48 & reference & 0.439 & & \\
\hline Yes (28) & 5.65 & $0.17(-0.26,0.60)$ & & & \\
\hline \multicolumn{6}{|l|}{ Maternal education } \\
\hline Below high school (38) & 5.80 & reference & 0.020 & reference & 0.039 \\
\hline High school and above (45) & 5.32 & $-0.47(-0.87,-0.08)$ & & $-0.41(-0.79,-0.02)$ & \\
\hline \multicolumn{6}{|l|}{ Parental monthly income $e^{e}$} \\
\hline$\leq$ regional minimum salary (63) & 5.62 & reference & 0.122 & reference & 0.130 \\
\hline > regional minimum salary (19) & 5.24 & $-0.38(-0.86,0.10)$ & & $-0.34(-0.78,0.10)$ & \\
\hline \multicolumn{6}{|l|}{ Children $<5 y$ in the household } \\
\hline $1(68)$ & 5.45 & reference & 0.055 & reference & 0.021 \\
\hline 2 or more (15) & 5.96 & $0.51(-0.01,1.02)$ & & $0.59(0.09,1.09)$ & \\
\hline \multicolumn{6}{|l|}{ URTI symptoms ${ }^{f}$} \\
\hline No (61) & 5.44 & reference & 0.118 & & \\
\hline Yes (22) & 5.81 & $0.36(-0.09,0.82)$ & & & \\
\hline \multicolumn{6}{|l|}{ Exposure to cigarette smoke } \\
\hline No (48) & 5.46 & reference & 0.333 & reference & 0.127 \\
\hline Yes (35) & 5.66 & $0.20(-0.21,0.61)$ & & $0.29(-0.08,0.67)$ & \\
\hline \multicolumn{6}{|l|}{ Wood-fuelled stove in home } \\
\hline No (74) & 5.62 & reference & 0.020 & reference & 0.005 \\
\hline Yes (9) & 4.87 & $-0.76(-1.39,-0.12)$ & & $-0.91(-1.53,-0.28)$ & \\
\hline \multicolumn{6}{|l|}{ M. catarrhalis carriage } \\
\hline No (35) & 5.26 & reference & 0.019 & reference & 0.053 \\
\hline Yes (48) & 5.74 & $0.48(0.08,0.88)$ & & $0.37(-0.01,0.74)$ & \\
\hline \multicolumn{6}{|l|}{ S. pneumoniae carriage } \\
\hline No (35) & 5.31 & reference & 0.056 & reference & 0.229 \\
\hline Yes (48) & 5.71 & $0.39(-0.01,0.80)$ & & $0.23(-0.15,0.61)$ & \\
\hline \multicolumn{6}{|l|}{ S. aureus carriage } \\
\hline No (81) & 5.53 & reference & 0.734 & & \\
\hline Yes (2) & 5.76 & $0.23(-1.10,1.56)$ & & & \\
\hline
\end{tabular}

${ }^{\mathrm{a}} H$. influenzae density reported in $\log _{10}$ genome equivalents $/ \mathrm{ml}$

${ }^{\mathrm{b}}$ Coefficient is the difference in means determined by linear regression

${ }^{\mathrm{C}}$ Adjusted for residence type, maternal education, income, 2 or more children $<5 y$, cigarette smoke exposure, wood-fuelled stove, $M$. catarrhalis carriage, and S. pneumoniae carriage

${ }^{\mathrm{d}}$ Stunting (chronic undernutrition) defined as length/height-for-age $z$-score below -2 standard deviations of the median

${ }^{e}$ Regional minimum salary rates (2016) were 1,800,725 Indonesian rupiah (IDR) in Padang, 2,626,940 IDR in Bandung, and 1,550,000 IDR in Lombok

fUpper respiratory tract infection (URTI) symptoms include rhinorrhea, cough, and/or tonsillitis 
Table 5 Linear regression analysis of factors associated with M. catarrhalis density in children who are carriers $(n=129)$

\begin{tabular}{|c|c|c|c|c|c|}
\hline Variable $(\mathrm{n})$ & Mean density $\left(\log _{10} \mathrm{GE} / \mathrm{ml}\right)^{\mathrm{a}}$ & Unadjusted coefficient ${ }^{\mathrm{b}}(95 \% \mathrm{Cl})$ & $P$ value & Adjusted coefficient ${ }^{\mathrm{C}}(95 \% \mathrm{Cl})$ & $P$ value \\
\hline \multicolumn{6}{|l|}{ Region } \\
\hline Padang (32) & 6.12 & reference & 0.010 & reference & 0.165 \\
\hline Bandung (45) & 6.46 & $0.34(-0.14,0.82)$ & & $0.28(-0.22,0.78)$ & \\
\hline Lombok (52) & 5.81 & $-0.31(-0.77,0.15)$ & & $-0.18(-0.68,0.33)$ & \\
\hline \multicolumn{6}{|l|}{ Sex } \\
\hline Female (62) & 6.12 & reference & 0.995 & & \\
\hline Male (67) & 6.12 & $0.00(-0.37,0.36)$ & & & \\
\hline \multicolumn{6}{|l|}{ Residence } \\
\hline Urban (57) & 6.08 & reference & 0.748 & reference & 0.980 \\
\hline Semi-rural (72) & 6.14 & $0.06(-0.32,0.44)$ & & $-0.01(-0.41,0.40)$ & \\
\hline Age & 6.12 & $-0.04(-0.10,0.01)$ & 0.126 & & \\
\hline \multicolumn{6}{|l|}{ Stunting $^{d}$} \\
\hline No (82) & 6.02 & reference & 0.177 & & \\
\hline Yes (47) & 6.28 & $0.26(-0.12,0.65)$ & & & \\
\hline \multicolumn{6}{|l|}{ Maternal education } \\
\hline Below high school (65) & 6.22 & reference & 0.258 & & \\
\hline High school and above (64) & 6.01 & $-0.21(-0.58,0.16)$ & & & \\
\hline \multicolumn{6}{|l|}{ Parental monthly income $e^{e}$} \\
\hline$\leq$ regional minimum salary (92) & 6.11 & reference & 0.885 & reference & 0.767 \\
\hline$>$ regional minimum salary (35) & 6.08 & $-0.03(-0.45,0.39)$ & & $-0.06(-0.49,0.36)$ & \\
\hline \multicolumn{6}{|l|}{ Children $<5 y$ in the household } \\
\hline $1(100)$ & 6.06 & reference & 0.297 & & \\
\hline 2 or more (27) & 6.30 & $0.24(-0.22,0.70)$ & & & \\
\hline \multicolumn{6}{|l|}{ URTI symptoms ${ }^{f}$} \\
\hline No (92) & 5.94 & reference & 0.003 & reference & 0.035 \\
\hline Yes (37) & 6.55 & $0.61(0.21,1.01)$ & & $0.46(0.03,0.88)$ & \\
\hline \multicolumn{6}{|l|}{ Exposure to cigarette smoke } \\
\hline No (69) & 6.10 & reference & 0.863 & reference & 0.526 \\
\hline Yes (60) & 6.13 & $0.03(-0.34,0.41)$ & & $0.12(-0.27,0.52)$ & \\
\hline \multicolumn{6}{|l|}{ Wood-fuelled stove in home } \\
\hline No (113) & 6.17 & reference & 0.117 & reference & 0.534 \\
\hline Yes (16) & 5.72 & $-0.45(-1.01,0.11)$ & & $-0.20(-0.83,0.43)$ & \\
\hline \multicolumn{6}{|l|}{ H. influenzae carriage } \\
\hline No (81) & 6.05 & reference & 0.351 & & \\
\hline Yes (48) & 6.23 & $0.18(-0.20,0.57)$ & & & \\
\hline \multicolumn{6}{|l|}{ S. pneumoniae carriage } \\
\hline No (45) & 5.87 & reference & 0.059 & reference & 0.207 \\
\hline Yes (84) & 6.25 & $0.37(-0.01,0.76)$ & & $0.25(-0.14,0.65)$ & \\
\hline \multicolumn{6}{|l|}{ S. aureus carriage } \\
\hline No (128) & 6.11 & reference & 0.236 & & \\
\hline Yes (1) & 7.38 & $1.27(-0.84,3.39)$ & & & \\
\hline
\end{tabular}

${ }^{\mathrm{a}} M$. cattarhalis density reported in $\log _{10}$ genome equivalents $/ \mathrm{ml}$

${ }^{b}$ Coefficient is the difference in means determined by linear regression

'Adjusted for region, residence type, income, upper respiratory tract infection (URTI) symptoms, cigarette smoke exposure, wood-fuelled stove, and S.

pneumoniae carriage

dStunting (chronic undernutrition) defined as length/height-for-age z-score below -2 standard deviations of the median

e Regional minimum salary rates (2016) were 1,800,725 Indonesian rupiah (IDR) in Padang, 2,626,940 IDR in Bandung, and 1,550,000 IDR in Lombok

fURTI symptoms include rhinorrhea, cough, and/or tonsillitis 
species at high density may be causative of the observed symptoms, the presence of respiratory symptoms creates an environment that favors bacterial growth, or both.

A limitation of our study is that respiratory viruses were not assessed. There is mounting evidence that they play a role in pneumococcal carriage density. A study conducted on children in day-care in Portugal found that pneumococcal colonization was associated with rhinitis symptoms, consistent with our findings, and pneumococcal density was significantly higher in children who tested positive for a respiratory virus [25]. In a randomized trial of live attenuated influenza vaccine (LAIV) in the UK, children who received the vaccine had significantly higher pneumococcal density in the nasopharynx 28 days after vaccination compared to controls [37]. In rural children under the age of three in Peru, pneumococcal densities were higher during acute respiratory illness $(p<0.0001)$, and higher in children who tested positive for a respiratory virus compared to those who were virus-negative. (median $\log _{10}$ transformed density 4.73 vs 3.94 , respectively; adjusted $p=0.06$ ) [38]. Based upon these findings, it is likely that some children in our study who had URTI symptoms and high pneumococcal density may have been co-infected with a respiratory virus. A recent study in American children aged 4-7 years reported that pneumococcal densities were higher when a respiratory virus was detected, regardless of whether the children displayed URTI symptoms [39]. These data suggest that respiratory viruses may influence bacterial density in asymptomatic children as well as those experiencing respiratory infections. Viral testing is recommended for future studies on risk factors for bacterial carriage.

For M. catarrhalis, there are few published data examining density, however children in Tanzania with severe pneumonia had increased density of $M$. catarrhalis in their nasopharynx compared to children with mild URTI [40]. In our study, we did not find an association between $\mathrm{H}$. influenzae density and URTI symptoms. In the Portuguese day care study, rhinitis symptoms were associated with increased $H$. influenzae density, but in the LAIV trial, vaccine recipients did not have higher $H$. influenzae density compared to controls [25, 37]. The relationship between $H$. influenzae density and URTI symptoms may depend on the study population and/or respiratory virus.

We sought to examine the effects of smoke exposure on carriage of potentially pathogenic bacteria by including exposure to cigarette smoke and the presence of woodfuelled stoves in the home as variables. Unlike a study on children aged 1-59 months in Israel, and a study that included children aged 6-60 months and 45-70 year old adults in Semarang, Indonesia, we did not find an association between pneumococcal carriage and cigarette smoke exposure $[29,41]$. However, studies on children and teenagers conducted in the Netherlands and the UK similarly did not find an association with cigarette smoke exposure, nor did two earlier studies conducted in Lombok, Indonesia [30, 31, 42, 43]. Levels of smoke exposure are difficult to ascertain without detailed monitoring, and our analysis did not incorporate whether the smoker in the household was the mother, father, or other relative. Wood-fuelled stoves, which can contribute to indoor air pollution and are associated with increased risk of pneumonia, likewise were not a risk factor for bacterial carriage in our study [44]. Unexpectedly, the presence of wood-fuelled stoves was associated with decreased density of $H$. influen$z a e$ and S. aureus. Most Indonesian households use liquefied petroleum gas (LPG) stoves as LPG is subsidized by the government. Relatively few participants in our study reported having a wood-fuelled stove, and some of those who did also had an LPG stove. Due to the small numbers these results should be interpreted with caution.

The high prevalence $(26.8 \%)$ of stunting, an indicator of chronic undernutrition, in our study was consistent with 2013 national data from Indonesia showing stunting in $36.4 \%$ of children under the age of five (https:// data.worldbank.org/) and a 2011 study reporting 28.4\% stunting in children under 24 months [45]. Stunting is a recognized risk factor for pneumonia in children, as well as for poor outcomes in pediatric pneumonia [46, 47]. Recently, stunting was identified as a risk factor for S. pneumoniae carriage in Warao Amerindians in Venezuela aged $0-4$ years [48]. In our study, stunting was associated with increased odds of carriage for S. pneumoniae and M. catarrhalis, and increased S. pneumoniae density in univariable analysis, but these associations were no longer significant for S. pneumoniae following adjustment. However, taken together, data suggest that children with chronic malnutrition are more susceptible to colonization and/or high density carriage by potentially pathogenic bacteria, which may increase their risk of bacterial infections. Interventions to improve childhood nutrition as a potential strategy to reduce infections in at-risk populations may be worthy of investigation.

Low maternal education and having two or more children under five years in the household were associated with increased density of $H$. influenzae. These data, along with the association between low family income and higher density of S. pneumoniae, suggest that factors related to socio-economic status and exposure (interaction with other young children) may increase carriage density of some pathogens in addition to increasing risk of carriage. To our knowledge, these are the first published data linking socio-economic factors to bacterial carriage density.

\section{Conclusions}

Our study findings highlight the importance of socioeconomic factors, such as maternal education levels and 
having multiple young children in the household, as risk factors for carriage of potentially pathogenic bacteria. Stunting, a recognized public health problem in Indonesia, was linked to increased pathogen carriage and density. These factors are indicative of poverty, as are the majority of risk factors associated with pneumonia in children [2]. Our results provide further data demonstrating the association between URTIs and pathogen presence and density in the nasopharynx. There is growing evidence that bacterial density in the nasopharynx can play a role in development of pneumonia and other infections, as well as pathogen transmission. Here, we provide novel data on host and environmental factors associated with bacterial density.

\section{Additional file}

Additional file 1: Table S1. Univariable and multivariable analysis of risk factors for $\mathrm{H}$. influenzae and S.aureus carriage. Table S2. Univariable and multivariable analysis of risk factors for carriage of two or more of the following species: S. pneumoniae, H. influenzae, M. catarrhalis, and S. aureus. Table S3. Linear regression analysis of factors associated with $S$. aureus density in children who are carriers $(n=22)$. Table S4. Linear regression analysis of factors associated with the combined density of $S$. pneumoniae, $H$. influenzae, M. catarrhalis, and/or S. aureus in children colonized with of two or more bacterial species $(n=125)$. (DOCX $50 \mathrm{~kb}$ )

\section{Abbreviations}

aOR: adjusted odds ratio; Cl: Confidence intervals; GE: Genome equivalents; Hib: Haemophilus influenzae type B; HIV: Human immunodeficiency virus; IDR: Indonesian rupiah; LAIV: Live attenuated influenza vaccine; LPG: Liquid petroleum gas; OR: Odds ratio; PCR: Polymerase chain reaction; PCV: Pneumococcal conjugate vaccine; qPCR: real-time quantitative PCR; UK: United Kingdom; URTI: Upper respiratory tract infection; WHO: World Health Organization

\section{Acknowledgements}

The authors wish to thank the study participants and their families, and the doctors and health center staff from Puskesmas Puter and Puskesmas Jaya Mekar (Bandung region), Puskesmas Praya and Puskesmas Ubung (Lombok region), and Puskesmas Padang Timur and Puskesmas Bungus (Padang region). We acknowledge the laboratory team from the UNPAD microbiology laboratory for sample processing.

\section{Funding}

This study was funded by PATH Vaccine Solutions. Murdoch Children's Research institute was supported by the Victorian Government's Operational Infrastructure Support Program. Funders had no role in study design, collection, analysis, and interpretation of data, or manuscript preparation.

\section{Availability of data and materials}

The data that support the findings of this study are available from the corresponding author upon reasonable request, subject to approval by the Health Research Ethics Committee, Universitas Padjadaran Faculty of Medicine.

\section{Authors' contributions}

CK, KM, EMD, CM, SS, EW, CS, EF, RT, SAKI, KR, NED, and FFY contributed to study design. CK oversaw the study. EF, RT, SAKI, KR, NED, FFY, and CK conducted clinical procedures. CM, SS, and EMD conducted laboratory analyses. EF and EMD analyzed data with guidance from CN. EF and EMD wrote the manuscript and CS, EW, and CN provided critical feedback on the manuscript. All authors read and approved the final manuscript.

\section{Ethics approval and consent to participate}

Study procedures were approved by the Health Research Ethics Committee, Universitas Padjadaran Faculty of Medicine, Indonesia and the Royal Children's Hospital Human Research Ethics Committee, Australia (reference number 35258). Written informed consent was obtained from parents/ guardians of study participants.

\section{Consent for publication}

Not applicable.

\section{Competing interests}

The authors declare that they have no competing interests.

\section{Publisher's Note}

Springer Nature remains neutral with regard to jurisdictional claims in published maps and institutional affiliations.

\section{Author details}

${ }^{1}$ Department of Child Health, Universitas Padjadjaran/Hasan Sadikin General Hospital, Bandung, West Java, Indonesia. ${ }^{2}$ Pneumococcal Research, Murdoch Children's Research Institute, Parkville, VIC, Australia. ${ }^{3}$ Department of Paediatrics, The University of Melbourne, Parkville, VIC, Australia. ${ }^{4}$ Department of Biomedical Sciences, Division of Microbiology, Universitas Padjadjaran, Bandung, West Java, Indonesia. ${ }^{5}$ Department of Microbiology and Immunology, The University of Melbourne at the Peter Doherty Institute for Infection and Immunity, Parkville, VIC, Australia. ${ }^{6}$ District Health Office of Central Lombok, Praya, West Nusa Tenggara, Indonesia. ${ }^{7}$ West Nusa Tenggara Province General Hospital, Mataram, West Nusa Tenggara, Indonesia. ${ }^{8}$ Department of Child Health, Universitas Andalas, Padang, West Sumatra, Indonesia. ${ }^{9}$ London School of Hygiene and Tropical Medicine, London, UK.

Received: 5 June 2018 Accepted: 29 November 2018

Published online: 25 December 2018

\section{References}

1. Liu L, Oza S, Hogan D, Chu Y, Perin J, Zhu J, et al. Global, regional, and national causes of under-5 mortality in 2000-15: an updated systematic analysis with implications for the sustainable development goals. Lancet. 2016;388(10063):3027-35.

2. Rudan I, Boschi-Pinto C, Biloglav Z, Mulholland K, Campbell H. Epidemiology and etiology of childhood pneumonia. Bull World Health Organ. 2008;86(5): 408-16.

3. Murphy TF, Bakaletz LO, Smeesters PR. Microbial interactions in the respiratory tract. Pediatr Infect Dis J. 2009:28(10):S121-6.

4. Bogaert D, de Groot R, Hermans PWM. Streptococcus pneumoniae colonisation: the key to pneumococcal disease. Lancet Infect Dis. 2004;4(3): 144-54.

5. Adegbola RA, DeAntonio R, Hill PC, Roca A, Usuf E, Hoet B, et al. Carriage of Streptococcus pneumoniae and other respiratory bacterial pathogens in low and lower-middle income countries: a systematic review and meta-analysis. PLoS One. 2014:9(8):e103293.

6. Watson K, Carville K, Bowman J, Jacoby P, Riley TV, Leach AJ. Upper respiratory tract bacterial carriage in Aboriginal and non-Aboriginal children in a semi-arid area of Western Australia. Pediatr Infect Dis J. 2006 Sep;25(9): 782-90.

7. Dunne EM, Manning J, Russell FM, Robins-Browne RM, Mulholland EK, Satzke C. Effect of pneumococcal vaccination on nasopharyngeal carriage of Streptococcus pneumoniae, Haemophilus influenzae, Moraxella catarrhalis, and Staphylococcus aureus in Fijian children. J Clin Microbiol. 2012;50(3):1034-8.

8. Kwambana B, Barer M, Bottomley C, Adegbola R, Antonio M. Early acquisition and high nasopharyngeal co-colonisation by Streptococcus pneumoniae and three respiratory pathogens amongst Gambian new-borns and infants. BMC Infect Dis. 2011;11(1):175

9. Regev-Yochay G, Raz M, Dagan R, Porat N, Shainberg B, Pinco E, et al. Nasopharyngeal carriage of Streptococcus pneumoniae by adults and children in community and family settings. Clin Infect Dis. 2004;38:632-9.

10. Toledo ME, Casanova MF, Linares-Pérez N, García-Rivera D, Toraño Peraza G, Barcos Pina l, et al. Prevalence of pneumococcal nasopharyngeal carriage among. Children 2-18 months of age: baseline study pre introduction of pneumococcal vaccination in Cuba. Pediatr Infect Dis J. 2017;36(1):e22-8.

11. Abdullahi O, Nyiro J, Lewa P, Slack M, Scott JAG. The descriptive epidemiology of Streptococcus pneumoniae and Haemophilus influenzae nasopharyngeal carriage in children and adults in Kilifi District, Kenya. Pediatr Infect Dis J. 2008;27. 
12. Labout JAM, Duijts $L$, Arends LR, Jaddoe WWV, Hofman A, de Groot $R$, et al. Factors associated with pneumococcal carriage in healthy Dutch infants: the Generation R Study. J Pediatr. 2008;153(6):771-6 e771.

13. Jourdain S, Smeesters PR, Denis O, Dramaix M, Sputael V, Malaviolle X, Van Melderen $\mathrm{L}$, Vergison A. Differences in nasopharyngeal bacterial carriage in preschool children from different socio-economic origins. Clin Microbiol Infect. 2011;17(6):907-14.

14. Principi N, Marchisio P, Schito GC, Mannelli S. Ascanius project collaborative group. Risk factors for carriage of respiratory pathogens in the nasopharynx of healthy children. Pediatr Infect Dis J. 1999;18(6):517-23.

15. Hanieh S, Hamaluba M, Kelly DF, Metz JA, Wyres KL, Fisher R, et al. Streptococcus pneumoniae carriage prevalence in Nepal: evaluation of a method for delayed transport of samples from remote regions and implications for vaccine implementation. PLoS One. 2014;9(6):e98739.

16. Neto AS, Lavado P, Flores $P$, Dias $R$, Pessanha MA, Sousa E, et al. Risk factors for the nasopharyngeal carriage of respiratory pathogens by Portuguese children: phenotype and antimicrobial susceptibility of Haemophilus influenzae and Streptococcus pneumoniae. Microb Drug Resist. 2003;9(1):99-108.

17. Kinabo GD, Ven A, Msuya L, Shayo AM, Schimana W, Ndaro A, et al. Dynamics of nasopharyngeal bacterial colonisation in HIV-exposed young infants in Tanzania. Tropical Med Int Health. 2013;18:286-95.

18. Verani JR, Massora S, Acácio S, dos Santos RT, Vubil D, Pimenta F, et al. Nasopharyngeal carriage of Streptococcus pneumoniae among HIV-infected and -uninfected children $<5$ years of age before introduction of pneumococcal conjugate vaccine in Mozambique. PLoS One. 2018;13 e0191113.

19. Madhi SA, Adrian P, Kuwanda L, Cutland C, Albrich WC, Klugman KP. Long term effect of pneumococcal conjugate vaccine on nasopharyngeal colonization by Streptococcus pneumoniae - and associated interactions with Staphylococcus aureus and Haemophilus influenzae colonization-in HIV-infected and HIV-uninfected children. J Infect Dis. 2007;196:1662-6.

20. Donkor ES, Annan JA, Badoe EV, Dayie NTKD, Labi A-K, Slotved H-C. Pneumococcal carriage among HIV infected children in Accra, Ghana. BMC Infect Dis. 2017;17:133.

21. Mulu W, Yizengaw E, Alemu M, Mekonnen D, Hailu D, Ketemaw K, et al. Pharyngeal colonization and drug resistance profiles of Morraxella catarrrhalis, Streptococcus pneumoniae, Staphylococcus aureus, and Haemophilus influenzae among HIV infected children attending ART Clinic of Felegehiwot referral hospital, Ethiopia. PloS One. 2018;13:e0196722.

22. Vu HTT, Yoshida LM, Suzuki M, Nguyen HAT, Nguyen CDL, Nguyen ATT, et al. Association between nasopharyngeal load of Streptococcus pneumoniae, viral coinfection, and radiologically confirmed pneumonia in Vietnamese children. Pediatr Infect Dis J. 2011;30(1):11-8.

23. Short KR, Reading PC, Wang N, Diavatopoulos DA, Wijburg OL. Increased nasopharyngeal bacterial titers and local inflammation facilitate transmission of Streptococcus pneumoniae. MBio. 2012;3(5):e00255-12..

24. Binks M, Cheng A, Smith-Vaughan $H$, Sloots T, Nissen M, Whiley D, et al. Viral-bacterial co-infection in Australian indigenous children with acute otitis media. BMC Infect Dis. 2011;11(1):161.

25. Rodrigues F, Foster D, Nicoli E, Trotter C, Vipond B, Muir P, et al. Relationships between rhinitis symptoms, respiratory viral infections and nasopharyngeal colonization with Streptococcus pneumoniae, Haemophilus influenzae and Staphylococcus aureus in children attending daycare. Pediat Infect Dis J. 2013;32(3):227-32.

26. UNICEF: Committing to child survival: a promise renewed. Progress report; 2014.

27. Hodge A, Firth S, Marthias T, Jimenez-Soto E. Location Matters: Trends in inequalities in child mortality in Indonesia. Evidence from repeated crosssectional surveys. PLoS One. 2014;9(7):e103597.

28. Dunne EM, Murad C, Sudigdoadi S, Fadlyana E, Tarigan R, Indriyani SAK, Pell CL, Watts E, Satzke C, Hinds J, et al. Carriage of Streptococcus pneumoniae, Haemophilus influenzae, Moraxella catarrhalis, and Staphylococcus aureus in Indonesian children: a cross-sectional study. PLoS One. 2018;13(4):e0195098.

29. Farida $H$, Severin JA, Gasem MH, Keuter M, Wahyono $H$, van den Broek $P$, et al. Nasopharyngeal carriage of Streptococcus pneumonia in pneumoniaprone age groups in Semarang, Java Island, Indonesia. PLoS One. 2014;9(1): e87431.

30. Soewignjo S, Gessner BD, Sutanto A, Steinhoff M, Prijanto M, Nelson C, et al. Streptococcus pneumoniae nasopharyngeal carriage prevalence, serotype distribution, and resistance patterns among children on Lombok Island. Indonesia Clin Infect Dis. 2001;32(7):1039-43.

31. Hadinegoro SR, Prayitno A, Khoeri MM, Djelantik IG, Dewi NE, Indriyani SA et al. Nasopharyngeal carriage of Streptococcus pneumoniae in healthy children under five years old in Central Lombok regency, Indonesia. Southeast Asian J Trop Med Public Health. 2016;47(3):485-93.

32. Mercedes $\mathrm{O}$. WHO child growth standards based on length/height, weight and age. Acta Paediatr. 2006;95(S450):76-85.

33. Satzke C, Turner P, Virolainen-Julkunen A, Adrian PV, Antonio M, Hare KM, et al. Standard method for detecting upper respiratory carriage of Streptococcus pneumoniae: updated recommendations from the World Health Organization pneumococcal carriage working group. Vaccine. 2013; 32(1):165-79.

34. Carvalho Mda G, Tondella ML, McCaustland K, Weidlich L, McGee L, Mayer LW, et al. Evaluation and improvement of real-time PCR assays targeting lytA, ply, and psaA genes for detection of pneumococcal DNA. J Clin Microbiol. 2007:45(8):2460-6.

35. Januraga PP, Reekie J, Mulyani T, Lestari BW, Iskandar S, Wisaksana R, et al. The cascade of HIV care among key populations in Indonesia: a prospective cohort study. Lancet HIV. 2018 Oct;5(10):e560-8.

36. Roca A, Bottomley C, Hill PC, Bojang A, Egere U, Antonio M, et al. Effect of age and vaccination with a pneumococcal conjugate vaccine on the density of pneumococcal nasopharyngeal carriage. Clin Infect Dis. 2012;55: 816-24.

37. Thors V, Christensen H, Morales-Aza B, Vipond I, Muir P, Finn A. The effects of live attenuated influenza vaccine on nasopharyngeal bacteria in healthy 2 to 4 year olds. A randomized controlled trial. Am J Respir Crit Care Med. 2016;193(12):1401-9.

38. Fan RR, Howard LM, Griffin MR, Edwards KM, Zhu Y, Williams JV, et al. Nasopharyngeal pneumococcal density and evolution of acute respiratory illnesses in young children, Peru, 2009-2011. Emerg Infect Dis. 2016;22(11): 1996-9.

39. DeMuri GP, Gern JE, Eickhoff JC, Lynch SV, Wald ER. Dynamics of bacterial colonization with Streptococcus pneumoniae, Haemophilus influenzae, and Moraxella catarrhalis during symptomatic and asymptomatic viral upper respiratory tract infection. Clin Infect Dis. 2018;66(7):1045-53.

40. Chochua S, D'Acremont V, Hanke C, Alfa D, Shak J, Kilowoko M, et al. Increased nasopharyngeal density and concurrent carriage of Streptococcus pneumoniae, Haemophilus influenzae, and Moraxella catarrhalis are associated with pneumonia in febrile children. PLoS One. 2016;11(12): e0167725.

41. Greenberg D, Givon-Lavi N, Broides A, Blancovich I, Peled N, Dagan R. The contribution of smoking and exposure to tobacco smoke to Streptococcus pneumoniae and Haemophilus influenzae carriage in children and their mothers. Clin Infect Dis. 2006;42(7):897-903.

42. van Hoek AJ, Sheppard CL, Andrews NJ, Waight PA, Slack MPE, Harrison TG, et al. Pneumococcal carriage in children and adults two years after introduction of the thirteen valent pneumococcal conjugate vaccine in England. Vaccine. 2014;32(34):4349-55.

43. Bogaert $D$, van Belkum A, Sluijter M, Luijendijk $A$, de Groot R, Rümke HC, et al. Colonisation by Streptococcus pneumoniae and Staphylococcus aureus in healthy children. Lancet. 2004;363(9424):1871-2.

44. Dherani M, Pope D, Mascarenhas M, Smith KR, Weber M, Bruce N. Indoor air pollution from unprocessed solid fuel use and pneumonia risk in children aged under five years: a systematic review and meta-analysis. Bull World Health Organ. 2008;86(5):390-8

45. Torlesse H, Cronin AA, Sebayang SK, Nandy R. Determinants of stunting in Indonesian children: evidence from a cross-sectional survey indicate a prominent role for the water, sanitation and hygiene sector in stunting reduction. BMC Public Health. 2016;16:669.

46. Moschovis PP, Addo-Yobo EO, Banajeh S, Chisaka N, Christiani DC, Hayden $D$, et al. Stunting is associated with poor outcomes in childhood pneumonia. Tropical Med Int Health. 2015 Oct;20(10):1320-8.

47. Schlaudecker EP, Steinhoff MC, Moore SR. Interactions of diarrhea, pneumonia, and malnutrition in childhood: recent evidence from developing countries. Curr Opin Infect Dis. 2011;24(5):496-502.

48. Verhagen LM, Hermsen M, Rivera-Olivero IA, Sisco MC, de Jonge MI, Hermans PW, et al. Nasopharyngeal carriage of respiratory pathogens in Warao Amerindians: significant relationship with stunting. Tropical Med Int Health. 2017:22(4):407-14. 